\title{
Within-Field Variation of Fusarium graminearum Isolates for Aggressiveness and Deoxynivalenol Production in Wheat Head Blight
}

\author{
Firas Talas, Rasha Kalih, and Thomas Miedaner
}

First, second, and third authors: Universität Hohenheim, State Plant Breeding Institute (720), Stuttgart, Germany; and first and second authors: National Commission of Biotechnology (NCBT), P.O. Box 31902, Damascus, Syria.

Accepted for publication 2 September 2011.

\section{ABSTRACT}

Talas, F., Kalih, R., and Miedaner, T. 2012. Within-field variation of Fusarium graminearum isolates for aggressiveness and deoxynivalenol production in wheat head blight. Phytopathology 102:128-134.

Fusarium head blight (FHB), caused by Fusarium graminearum sensu stricto (s.s.), causes tremendous annual yield losses in wheat worldwide. Variation of aggressiveness of isolates from individual field populations in terms of FHB infection and deoxynivalenol (DON) concentration in the host are important population parameters reflecting parasitic ability. Our main objective was to estimate the variation of both traits within three populations of $F$. graminearum s.s., each consisting of 30 singlespore isolates collected from small wheat fields in Germany, and to compare it with 11 isolates of a collection ( $F$. graminearum collection) from four countries. The same isolates were characterized using 19 single-sequence repeat markers. All isolates were spray inoculated on a moderately resistant spring wheat cultivar at two field locations over

Fusarium graminearum Schwabe (teleomorph Gibberella zeae Schwein) is the main causal agent of Fusarium head blight (FHB) on wheat, other small cereals, and maize. F. graminearum sensu stricto (s.s.) is the predominant species causing FHB in wheat in the United States $(12,45)$ and central Europe (8), including Germany (38). FHB has a great economic impact on wheat all over the world due to severe yield losses. Damage due to FHB in the United States amounted to >US\$1 billion in 1993 and US\$500 million in 1994 (14). Economic impact of FHB is also caused by contamination of the harvest with the mycotoxins deoxynivalenol (DON), nivalenol (NIV), zearalenone, and others that cause toxicities to humans and animals. Mean percentage of natural FHB infection and DON concentration in harvested barley samples of the Red River Valley ranged from $11.8 \%$ (North Dakota, 1995) to $51.3 \%$ (Minnesota, 1994) and from $2.7 \mathrm{mg} \mathrm{kg}^{-1}$ (North Dakota, 1993) to $21.8 \mathrm{mg} \mathrm{kg}^{-1}$ (Minnesota, 1994), respectively (34). In southwest Germany, range and mean DON concentration from arbitrarily collected field samples of wheat were 0.004 to 20.54 and $1.63 \mathrm{mg} \mathrm{kg}^{-1}$, respectively (28). These studies document a high variation for the mentioned traits in natural infections.

A field population is defined as isolates sharing a common gene pool and originating from a limited geographical area, like a field (22), and reflects the lowest level of population differentiation. A significant amount of gene flow was reported among the U.S. populations (46). Gale et al. (12) reported the coexistence of

Corresponding author: T. Miedaner; E-mail address: miedaner@uni-hohenheim.de

http://dx.doi.org/10.1094/PHYTO-06-11-0162

(C) 2012 The American Phytopathological Society
2 years (i.e., in four environments). The genotypic proportion of phenotypic variance $\left(\sigma_{\mathrm{G}}^{2}\right)$ within populations was significant $(P<0.01)$ for both traits, and the $\sigma_{\mathrm{G}}^{2} \times$ environment interaction was even more important for mean FHB severity. Ranges in mean FHB severity and DON concentration in the host were only slightly smaller for the field populations than for the $F$. graminearum collection. Both traits were significantly $(P<0.05)$ correlated within and across populations. A further partitioning of $\sigma^{2}{ }_{\mathrm{G}}$ revealed $72 \%$ of $\sigma^{2}{ }_{\mathrm{G}}$ within and $28 \%$ of $\sigma^{2}{ }_{\mathrm{G}}$ across populations for both traits. Molecular variance of the three populations was similarly distributed $(73.6 \%$ within versus $26.4 \%$ between populations). In view of this high within-field variation for traits of parasitic ability and selection, neutral molecular markers, multiple resistance genes of different origin should be employed in wheat breeding programs to obtain a long-term stable FHB resistance.

Additional keywords: Gibberella zeae, mycotoxin. genetically divergent populations of $F$. graminearum s.s. in the upper Midwest and Gulf Coast regions of the United States. In a companion study, we reported a high molecular diversity within 12 individual field populations of $F$. graminearum s.s. in Germany, with a restricted diversity between them, using 19 simple sequence repeat (SSR) markers (38).

The general objective of this study was to measure the variation of aggressiveness within individual field populations as well as the DON concentration in wheat in the natural habitat and to connect them with the result of a marker study. The phenotypic variance (i.e., the variation of the observable trait in an experiment) can be partitioned into components of variance attributable to the following factors: genotype, genotype $\times$ environment interaction, and error (10). The genotypic variance $\left(\sigma_{\mathrm{G}}^{2}\right)$ is the variation caused by genetic differences among individuals as measured by phenotypic traits (10). To distinguish $\sigma_{\mathrm{G}}^{2}$ from the variance revealed by molecular markers, we call the latter "molecular variance". These terms will be used through out this article. The estimate of $\sigma^{2}$ for aggressiveness and DON concentration is a key feature of population genetics (22), a risk of adaptation of $F$. graminearum to new host genotypes is only given when a large extent of this variation is also present in natural populations $(22,23)$. Such an analysis should not be restricted to molecular markers or infections in the seedling stage $(25,26)$ but also estimated by fitness-related traits in adult plants in the natural habitat. In particular, we aimed to (i) divide the phenotypic variance into its components for the individual field populations, (ii) compare the phenotypic variation of individual field populations with a group of isolates from four countries, (iii) determine the within- and among-field variation of aggressiveness and the secreted DON concentration in the host, and (iv) compare phenotypic and molecular variation in these populations. 


\section{MATERIALS AND METHODS}

Fungal materials. Isolates of $F$. graminearum s.s. were sampled from three naturally infected wheat fields: Hohenheim $(\mathrm{HOH}$, 2008) in Baden-Württemberg in southwest Germany and Wetze (WET, 2006) and Schickelsheim (SCHICK, 2007) in Lower Saxony in north Germany. Thirty heads with typical FHB symptoms were arbitrarily collected from the front, middle, and end of each field. The area of the sampled fields was 1 to 3 ha. Geographic road distance from Hohenheim to Wetze is $456 \mathrm{~km}$, from Hohenheim to Schickelsheim is $555 \mathrm{~km}$, and from Wetze to Schickelsheim is $113 \mathrm{~km}$. In addition, eight isolates of $F$. graminearum s.s. sampled from Syria, Germany, Hungary, and Canada and three progenies from two cross populations were tested under the same environmental conditions for comparison (Table 1). These standard isolates were chosen because their aggressiveness was known from previous experiments (41) or their origin reflects a large geographic region from the Middle East to Central Europe to Canada.

Isolation, identification, and genotyping of isolates. All heads were frozen after sampling at $-20^{\circ} \mathrm{C}$ until isolation. Isolation started by picking one visually infected spikelet out of each head. Spikelets were disinfested by placing them in sodium hypochlorite $(2 \%)$ for $10 \mathrm{~min}$, followed by rinsing with sterile distilled water and then placing them in sulfate-streptomycin $(0.8 \%)$ for another $10 \mathrm{~min}$ and rinsing again with sterile distilled water modified after (21). Each spikelet was placed on an individual petri dish (diameter of $2.5 \mathrm{~cm}$ ) of synthesized nutrient agar (SNA) supplemented by streptomycin sulfate at $50 \mathrm{mg} \mathrm{liter}^{-1}$ modified after (19). Plates were incubated in the dark at $24^{\circ} \mathrm{C}$ for 2 days followed by exposition to continuous black light (Philips TLO, 40W/80; Royal Philips Electronics, Amsterdam, The Netherlands) at $20^{\circ} \mathrm{C}$ for 4 to 5 days. The formed macroconidia were transferred onto water agar (WA) plates (diameter of $9 \mathrm{~cm}$ ) for dilution. One single spore was picked out using the light microscope (Zeiss, Axioskop, Oberkochen, Germany) as visual means and transferred onto an SNA (diameter of $2.5 \mathrm{~cm}$ ) plate. After 2 to 3 days of mycelium growth on agar plates, several agar plugs were picked out and stored in 2-ml Eppendorf tubes filled with sterile water and kept at $6^{\circ} \mathrm{C}$ as a stock collection (20). Afterward, the same SNA plate was placed under continuous black light to induce massive sporulation. Spores were identified using light microscopy following the taxonomical key of Nelson et al. (30) for identification as F. graminearum sensu lato. Prior to this study, isolates were characterized for their species designation by generic primers designed from the translation elongation factor $1-\alpha$ gene (44); for their chemotype by the primers N11, 15D11, 3D11, and 11R (47); and for their marker loci by 19 SSR markers $(15,18,37)$. Details of DNA extraction and the molecular assays were previously described (38).

Inoculum production and inoculation. Four to six agar plugs out of the stored isolates were put into 1-liter Erlenmeyer flasks containing $300 \mathrm{ml}$ of nutrient-poor liquid medium (33). Cultures in flasks were grown on an orbital shaker $(110 \mathrm{rpm})$ with continuous black light illumination for 1 week at $22^{\circ} \mathrm{C}$. Macroconidia were harvested by filtering the culture through Miracloth (Merk KGaA, Darmstadt, Germany) and washing with autoclaved tap water $\left(\mathrm{H}_{2} \mathrm{O}\right)$. The spore suspensions were adjusted to $2 \times 10^{5}$ spores/ml following a count in a hemacytometer and frozen $\left(-80^{\circ} \mathrm{C}\right)$ in $100-\mathrm{ml}$ aliquots until used for inoculation. Spore germination rate was checked prior to inoculation and was $>90 \%$ in all instances. One aliquot was used to inoculate one field plot. For this, stored spore suspensions were thawed $\approx 2 \mathrm{~h}$ at room temperature $\left(18\right.$ to $21^{\circ} \mathrm{C}$ ) prior to application. Spores were inoculated on the wheat heads of each plot at full flowering of the wheat cultivar to ensure the maximum susceptibility period of wheat to $F$. graminearum (5), using a hand atomizer with constant air pressure of 3 bars from a tractor to ensure full coverage of all heads of the plot. There was no irrigation used.
Field experiment. Three populations, each consisting of 30 single-spore isolates and 11 isolates from an $F$. graminearum collection, were analyzed on the spring wheat 'Taifun' (KWS LOCHOW GmbH). Taifun was released in Germany in 2003 and has a FHB grade of 6 on a 1-to- 9 scale where $1=$ healthy and $9=$ highly susceptible (1). The experiment was planted at each of two locations in 2009 and 2010: Hohenheim $(\mathrm{HOH})$ (longitude $9^{\circ} 12^{\prime} 58^{\prime \prime}$, latitude $48^{\circ} 42^{\prime} 50^{\prime \prime}$, altitude $400 \mathrm{~m}$ ) and Oberer Lindenhof (OLI) (longitude $9^{\circ} 18^{\prime} 12^{\prime \prime}$, latitude $48^{\circ} 28^{\prime} 26^{\prime \prime}$, altitude $700 \mathrm{~m}$ ). In 2009 and 2010, the averages of annual temperature at $\mathrm{HOH}$ and OLI were 10.1 and $9.0^{\circ} \mathrm{C}$, respectively. The averages of annual precipitation at $\mathrm{HOH}$ and OLI were 643.2 and $722.8 \mathrm{~mm}$, respectively. Plants were grown in two-rowed microplots, $1 \mathrm{~m}$ in length and $0.42 \mathrm{~m}$ in width. Plots were arranged in a chessboard like design (i.e., each plot with a wheat entry was bordered by four plots of similar size that were planted with a long-strawed spring triticale ['Nilex'] to reduce interplot interference caused by drifting or secondary distribution of spores). Plots were machine sown with 220 kernels $\mathrm{m}^{-2}$, a seeding rate that results in homogeneous wheat stands of $\approx 200$ wheat ears $\mathrm{m}^{-2}$. To avoid infection by other pathogens, all plots were sprayed once with the fungicide Opus Top (Epoxiconazol at $84 \mathrm{~g} \mathrm{liter}^{-1}$ $\mathrm{ha}^{-1}+$ Fenpropimorph at $250 \mathrm{~g} \mathrm{liter}^{-1} \mathrm{ha}^{-1}$; BASF, Ludwigshafen, Germany) shortly before head emergence. The experiment had a split-plot design with two replications. The main-plot factor was the $F$. graminearum s.s. population and the subplot factor was the isolate. Both factors were assigned to a randomized complete block design. Five plots per replicate were left noninoculated to monitor the natural infection level. The isolates from the collection were grown as a small experiment adjacent to the populations in a randomized complete block design with three replications. Plots were harvested by hand at maturity and threshed in a single-head thresher (Fa. Walter-Wintersteiger, Austria), cleaned with reduced wind speed, and any remaining fragments of glumes and rachis were manually picked out. Cleaned wheat grain was ground in a commercial laboratory mill (Model 2A; Romer Labs, Inc., Union, MO) with a sieve size of $1 \mathrm{~mm}$ for DON analyses.

Phenotypic assessment. FHB severity was rated visually four times as the percentage of infected spikelets per plot (0 to 100\%). Individual FHB ratings began with the onset of symptom development (i.e., $\approx 14$ days after inoculation) and were continued at 3- to 4-day intervals until the beginning of the yellow ripening

TABLE 1. Name, origin, host, and year of collection of fungal materials used for inoculation

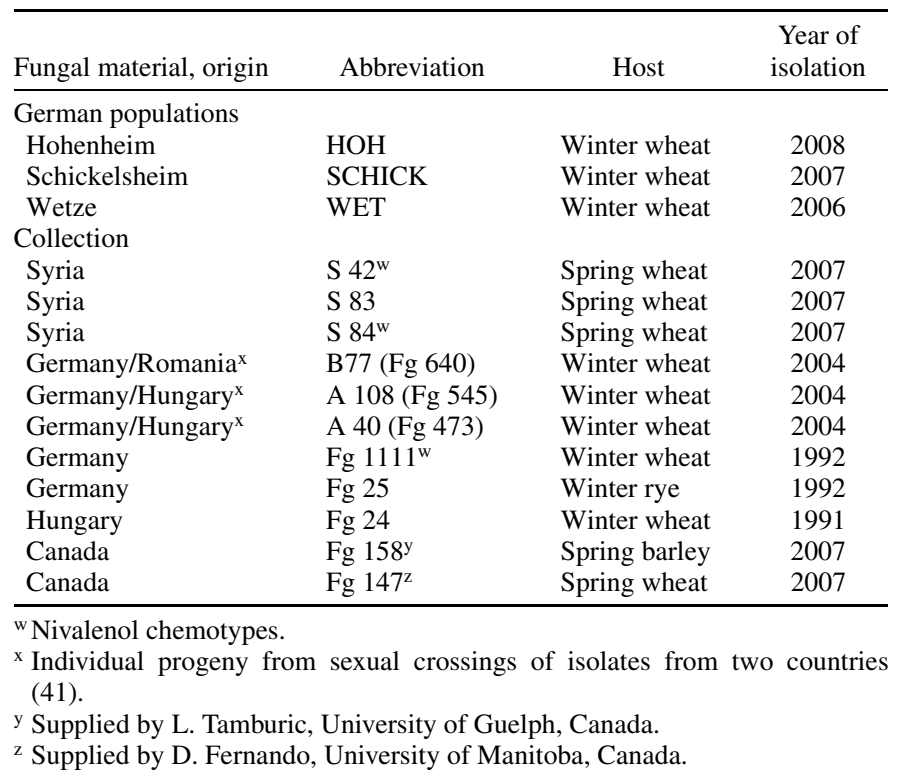


stage. The rating included both the number of infected spikes per plot and the number of infected spikelets per spike. Multiple ratings were applied to reflect the epidemiological development of the disease and to reduce the experimental error. Because the coefficients of correlation among ratings were tight $(r=0.96, P=$ 0.01 ), we present here the arithmetic means of the four ratings (= mean FHB rating) and the terminal FHB rating. The terminal FHB rating (i.e., the last rating in each environment) represents the maximum disease severity at the end of the epidemic.

All plots, including the noninoculated ones, were analyzed to quantify the amount of DON. Flour $(5 \mathrm{~g})$ from each grain sample was analyzed by using a commercially available enzyme immunoassay (enzyme-linked immunosorbent assay [ELISA]) (RIDASCREEN FAST DON; R-Biopharm GmbH, Darmstadt, Germany) as described in detail by Cumagun et al. (7). Reactions were evaluated as optical density at $405 \mathrm{~nm}$ using ELISA microplate reader TECAN sunrise (Männedorf, Switzerland). DON concentration was calculated using Magellan software provided by the manufacturer and calibrated against five standard solutions of DON in water $\left(0,0.22,0.67,2\right.$, and $\left.6 \mathrm{mg} \mathrm{kg}^{-1}\right)$ supplied by the manufacturer of the immunoassay.

Data analyses. All statistical analyses of field experiments were based on single-plot data. The independence and normal distribution of the residuals was verified by the PROC UNIVARIATE procedure. Mean FHB rating and DON concentration data were analyzed by analysis of variance procedures using the PROC GLM (general linear models). Locations were first calculated separately, and then the year-location combinations were analyzed as a series of environments with entry means and effective error mean squares (4). Phenotypic variation was partitioned according to the following linear model for both traits: $Y=\mu+P_{r}+$ $G(P)_{s r}+E_{z}+R(E)_{x z}+E P_{z r}+E G(P)_{z s r}+e$, where $Y$ were the phenotypic value, $\mu$ the overall mean, $P_{r}(r=1, \ldots 3)$ the populations, $G(P)_{s r}(s=1, \ldots 30)$ the genotypes nested within populations, $E_{z}(z=1, \ldots 4)$ the environments, $R_{x}(x=1,2)$ the

TABLE 2. Means of mean Fusarium head blight (FHB) rating, terminal FHB rating, and deoxynivalenol (DON) concentration of three field populations of Fusarium graminearum sensu stricto, each consisting of 30 isolates, and a collection of 11 isolates of $F$. graminearum sensu stricto (Collection) inoculated on spring wheat across four environments (Hohenheim $[\mathrm{HOH}]$ in 2009 and 2010 and Oberer Lindenhof [OLI] in 2009 and 2010)

\begin{tabular}{lccc}
\hline Fungal material & $\begin{array}{c}\text { Mean FHB } \\
\text { rating (\%) }\end{array}$ & $\begin{array}{c}\text { Terminal FHB } \\
\text { rating (\%) }\end{array}$ & $\begin{array}{c}\text { DON } \\
\text { concentration }\end{array}$ \\
\hline HOH & $31.19 \mathrm{~A}^{\mathrm{y}}$ & $57.97 \mathrm{~A}$ & $11.19 \mathrm{~A}$ \\
SCHICK & $31.14 \mathrm{~A}$ & $60.34 \mathrm{~A}$ & $12.30 \mathrm{~A}$ \\
WET & $27.85 \mathrm{~B}$ & $53.89 \mathrm{~B}$ & $9.40 \mathrm{~B}$ \\
Collection $^{\mathrm{z}}$ & 26.84 & 51.02 & 8.47
\end{tabular}

${ }^{\mathrm{y}}$ Numbers in each column followed by the same letter are not significantly

different $(P \leq 0.05)$ according to Tukey's multiple range test.

${ }^{\mathrm{z}}$ Without nivalenol-producing isolates. replicates, and $e$ the residual error of mean. Interaction effects were denoted by combination of the corresponding main effects. All effects were considered as random. Heritability $\left(h^{2}\right)$ was estimated on an entry-mean basis as the ratio of genotypic to
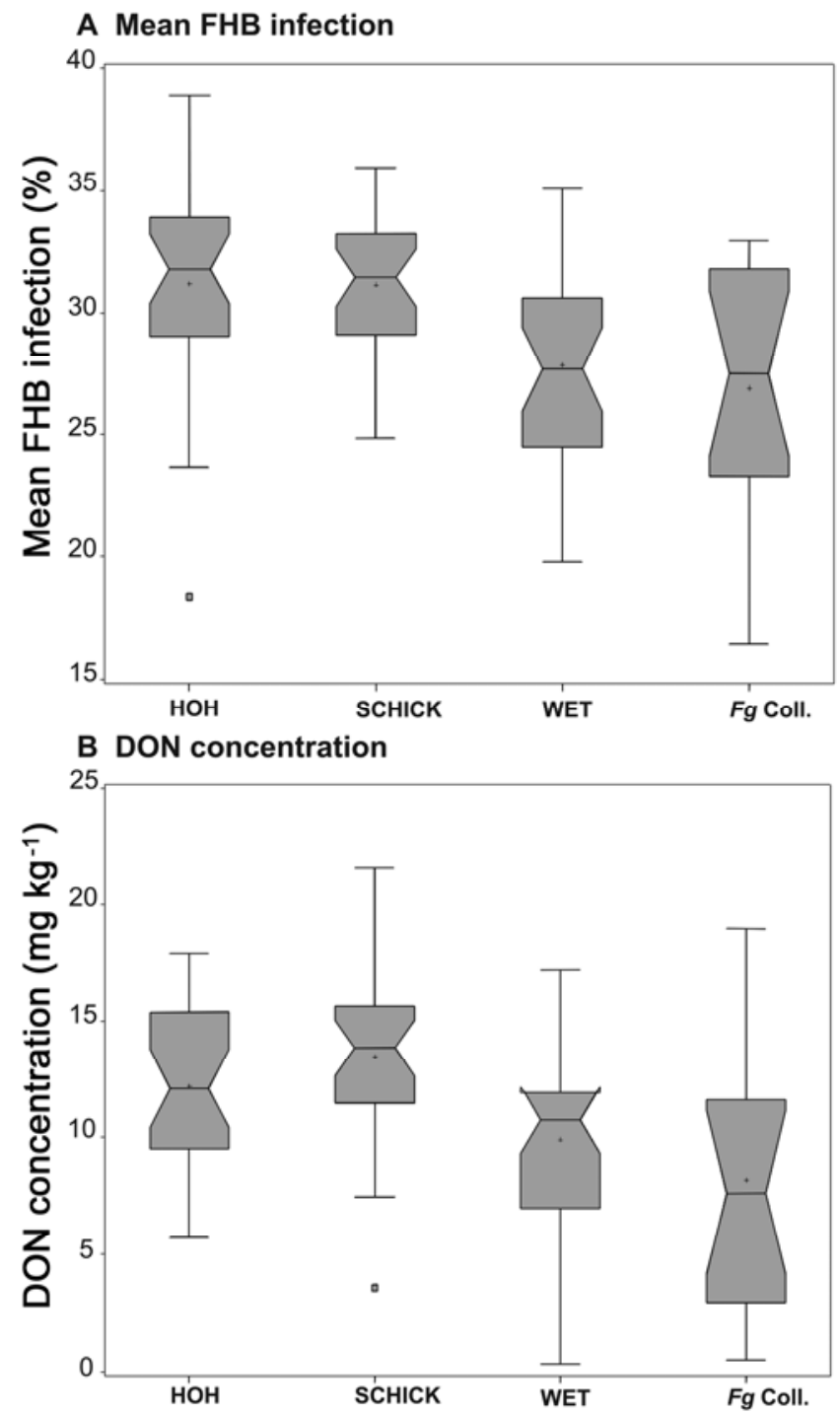

Fig. 1. Notched boxplots of mean Fusarium head blight (FHB) ratings and deoxynivalenol (DON) concentration for three field populations (Hohenheim $[\mathrm{HOH}]$, Wetze [WET], and Schickelsheim [SCHICK]), each consisting of 30 isolates, and the collection of 11 isolates of Fusarium graminearum sensu stricto ( $F g$ coll.) after inoculation on spring wheat across four environments; horizontal line within boxes $=$ median, $+=$ mean, $\square=$ outliers .

TABLE 3. Estimates of variance components and entry-mean heritabilities of mean Fusarium head blight rating (FHB) and deoxynivalenol (DON) concentration of three Fusarium graminearum sensu stricto populations, each consisting of 30 isolates, after inoculation on spring wheat across four environments (Hohenheim in 2009 and 2010 and Oberer Lindenhof in 2009 and 2010)

\begin{tabular}{|c|c|c|c|c|c|}
\hline \multirow[b]{2}{*}{ Parameter } & \multirow[b]{2}{*}{$\mathrm{df}^{\mathrm{y}}$} & \multicolumn{2}{|c|}{ Mean FHB } & \multicolumn{2}{|c|}{ DON concentration } \\
\hline & & Estimate & $P>F$ & Estimate & $P>F$ \\
\hline \multicolumn{6}{|l|}{ Source of variation } \\
\hline Population $(\mathrm{P})$ & 2 & 2.86 & $<0.0001$ & 2.66 & $<0.0001$ \\
\hline Genotypes $(\mathrm{G})$ within $\mathrm{P}\left(\sigma_{\mathrm{G}}^{2}\right)$ & 87 & 7.20 & $<0.0001$ & 6.83 & $<0.0001$ \\
\hline $\mathrm{E} \times \mathrm{P}$ & 6 & 1.30 & $<0.0001$ & 0.59 & 0.1375 \\
\hline Entry-mean heritability & $\ldots$ & 0.51 & $\ldots$ & 0.52 & $\ldots$ \\
\hline
\end{tabular}

${ }^{\mathrm{y}}$ Degrees of freedom.

${ }^{\text {z }}$ Negative estimate. 
phenotypic variance (10), following the formula $h^{2}=\sigma_{\mathrm{G}^{2}}^{2} / \sigma_{\mathrm{G}}^{2}+$ $\sigma_{\mathrm{GE}}^{2} / E+\sigma^{2} / E R$, where $\sigma_{\mathrm{G}}^{2}=$ genotypic variance, $\sigma_{\mathrm{GE}}^{2}=$ genotype $\times$ environment interaction variance, $\sigma^{2}=$ error variance, $E=$ number of environments, and $R=$ number of replications. PROC VARCOMP was used to estimate the variance components of mean FHB rating and DON concentration taking all factors as random. Means were compared using Tukey's multiple range test. All statistical analyses were performed by SAS software 9.1.2 (35).

Most isolates of each population and the $F$. graminearum collection were genotyped in a companion article (38) using 19 SSR markers together with isolates of nine other populations. The data of the populations $\mathrm{HOH}, \mathrm{SCHICK}$, and WET are first presented in this study separately. Number of detected alleles in each population, Nei's genetic diversity, and the analysis of molecular variance (AMOVA) were carried out using Arlequin 3.5 software (9). Simple matching index between all isolates over 19 SSR markers was performed according to the formula $d_{i j}=$ $u /(m+u)$, where $d_{i j}$ is the dissimilarity between two isolates, $u$ is the number of unshared alleles, and $m$ is the number of shared alleles (36). Principle coordinate analysis was performed in GenALEx 6.3 software (32); the values of the first three coordinates were plotted using PROC GPLOT in SAS 9.1.2 (35).

\section{RESULTS}

Inoculation led to similar mean FHB and terminal FHB ratings in three environments of 25 to 29 and 51 to $57 \%$, respectively, and DON concentrations of 9.5 to $12.0 \mathrm{mg} \mathrm{kg}^{-1}$, respectively (data not shown). In the fourth environment (HOH 2010), mean and terminal FHB ratings were 37 and $68 \%$ but DON concentration was not higher $\left(10.9 \mathrm{mg} \mathrm{kg}^{-1}\right)$. Mean FHB rating of the noninoculated plots across environments was $1.09 \%$ and mean DON concentration $0.48 \mathrm{mg} \mathrm{kg}^{-1}$. Mean and terminal FHB ratings and DON concentrations of the populations and the collection were rather similar (Table 2). From the three populations, only WET had significantly $(P<0.05)$ lower FHB ratings and DON concentration.

Partitioning of phenotypic variance revealed a significant $(P<$ 0.01 ) estimate of $\sigma_{\mathrm{G}}^{2}$ within populations for mean FHB rating and DON concentration as well (Table 3 ). The variance among popu- lations was considerably smaller, although significant $(P<0.01)$. Proportions of within versus between population variance were 72 versus $28 \%$, respectively, for both traits as calculated from the respective estimates of variance components (Table 3). For mean FHB rating, all other sources of variation were also significant; hence, the $\sigma_{G}^{2} \times$ environment interaction variance had the highest impact. In contrast, interactions with environments were not significant for DON concentration; here, $\sigma_{\mathrm{G}}^{2}$ was the most important variance component. Estimation of entry-mean heritability was moderate for mean FHB severity and DON concentration (0.51 and 0.52 , respectively).

Absolute ranges within populations were similar and large for all three populations and only slightly larger for the F. graminearum collection from Europe, Syria, and Canada, with average range differences for mean FHB rating of $15.8 \%$ and DON concentration of $16.3 \mathrm{mg} \mathrm{kg}^{-1}$ (Fig. 1). The larger variation in the $F$. graminearum collection was mainly due to the lower aggressiveness of three isolates being classified as NIV chemotypes. The notches of the boxes, however, did overlap, indicating no significantly different median of the four populations. Correlation between mean FHB rating and DON concentration was moderate within populations, ranging between $r=0.40$ and $0.66(0.05>$ $P<0.01$, without NIV chemotype isolates) (Fig. 2). Again, the $F$. graminearum collection had only a slightly higher variation than, for example, population WET. One isolate from WET (12D24) and three isolates (Fg1111, S42, and S84) from the F. graminearum collection population produced only very low DON concentrations in the wheat kernels but still had a mean FHB rating of 16 to $25 \%$. These isolates were profiled as NIV chemotype according to the molecular identification.

The average number of alleles ranged from 2.8 in SCHICK and the $F$. graminearum collection to 3.9 in $\mathrm{HOH}$ (Table 4). Similarly, Nei's genetic diversity showed a narrow range, with 0.49 in total. The AMOVA revealed that $74 \%$ was related to variation within populations versus $26 \%$ related to variation between populations. The molecular variance of the isolates were separated by principle coordinate analysis (PCoA) (Fig. 3). The isolates from the three field populations mainly grouped separately but some individual isolates were placed in a fourth group that resembled isolates from all populations, including the $F$. graminearum collection.

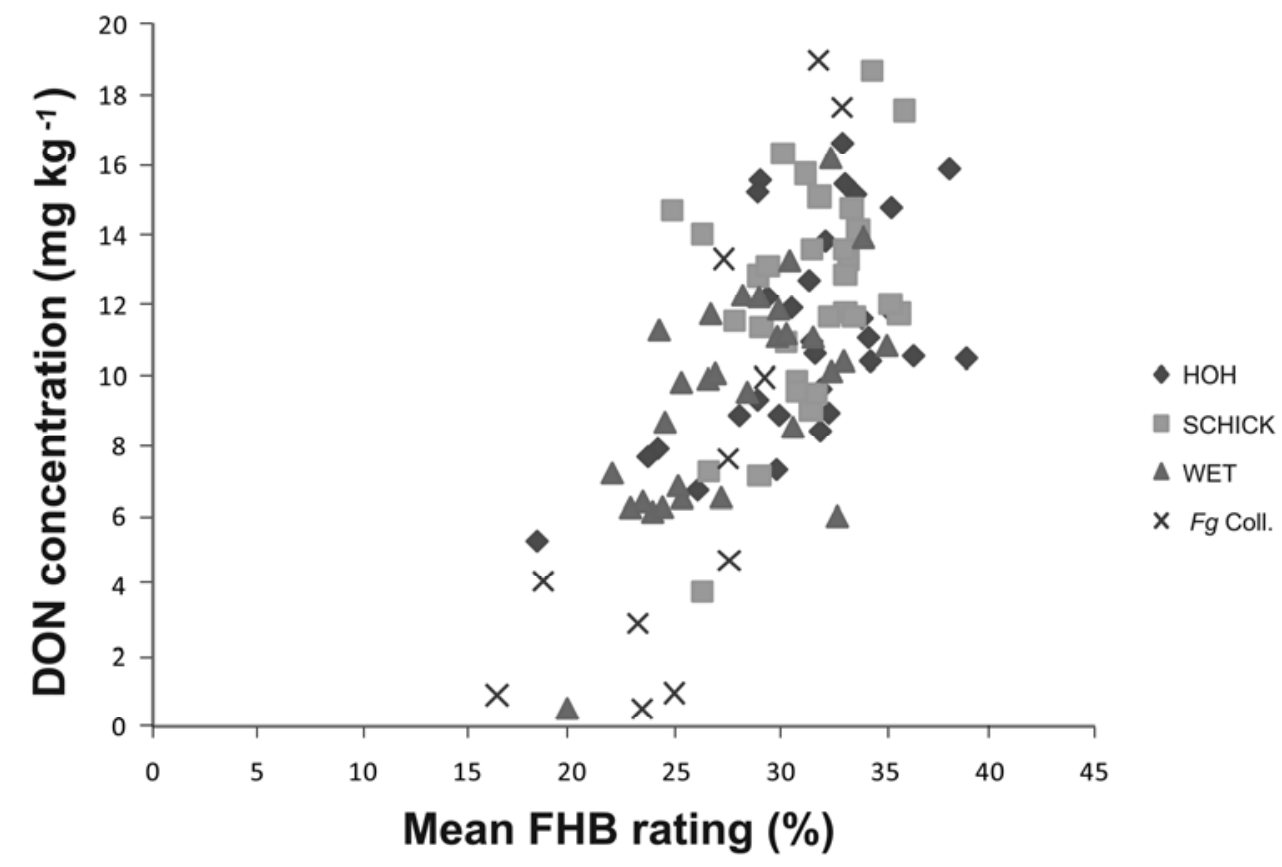

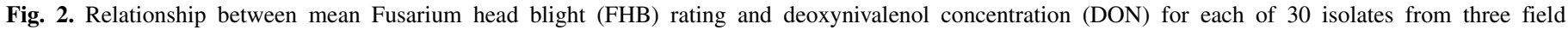

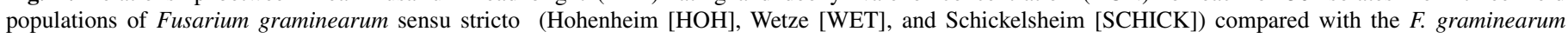
collection ( $\mathrm{Fg}$ coll.) of 11 isolates. 


\section{DISCUSSION}

In this study, we first analyzed within-field variation of populations of $F$. graminearum s.s. for aggressiveness and DON concentration in the natural habitat of the host in adult-plant stage by inoculation. The same isolates were also genotyped by 19 SSR markers (38). Consequently, we described the phenotypic and molecular variation among $F$. graminearum s.s. isolates collected from three individual naturally infected fields (field populations). In a previous study, $\mathrm{Xu}$ et al. (43) analyzed the within-field variation on the level of Fusarium spp. and chemotypes without evaluating the variation within species.

Mean FHB rating and DON concentrations in wheat showed a wide and significant $(P<0.01)$ range of variation within each field population that was only slightly different from the variation of the $F$. graminearum collection originating from four countries (Fig. 1). That no isolates of extremely low aggressiveness were detected in the field samples might be explained by the fact that we collected isolates only from visually diseased ears. Interestingly, the $F$. graminearum collection included four isolates of NIV chemotype with minimal DON production. In wheat, isolates with NIV chemotype belong to the group with lower aggressiveness $(24,29)$. A close association between FHB severity and DON concentration, as reported here again, was found in many studies before $(6,13,24,29)$; however, it should be noted that isolates also highly differ in their ability to produce mycelium during infection and no correlation was found between aggressiveness and DON concentration rate per unit fungal biomass $(7,13,24)$.

Estimate of $\sigma_{\mathrm{G}}^{2}$ was highly significant $(P<0.01)$ within each field population for both traits in each individual environment

TABLE 4. Average number of alleles, Nei's genetic diversity of three field populations of Fusarium graminearum sensu stricto and the $F$. graminearum collection, analysis of molecular variance (AMOVA), and Nei's genetic diversity of the three populations using 19 simple-sequence repeat markers (38)

\begin{tabular}{|c|c|c|c|c|}
\hline Fungal material & Number of isolates & Average number of alleles & Nei's genetic diversity & $\operatorname{AMOVA}(\%)$ \\
\hline \multicolumn{5}{|l|}{ Populations } \\
\hline Hohenheim & 28 & 3.9 & 0.44 & $\ldots$ \\
\hline Schickelsheim & 23 & 2.8 & 0.31 & $\ldots$ \\
\hline F. graminearum collection & 11 & 2.8 & 0.45 & $\ldots$ \\
\hline \multicolumn{5}{|c|}{ Partitioning of molecular variance } \\
\hline Total & $\ldots$ & $\ldots$ & 0.49 & 100.0 \\
\hline Within populations & $\ldots$ & $\ldots$ & 0.40 & 73.6 \\
\hline
\end{tabular}

\section{Coord.3}

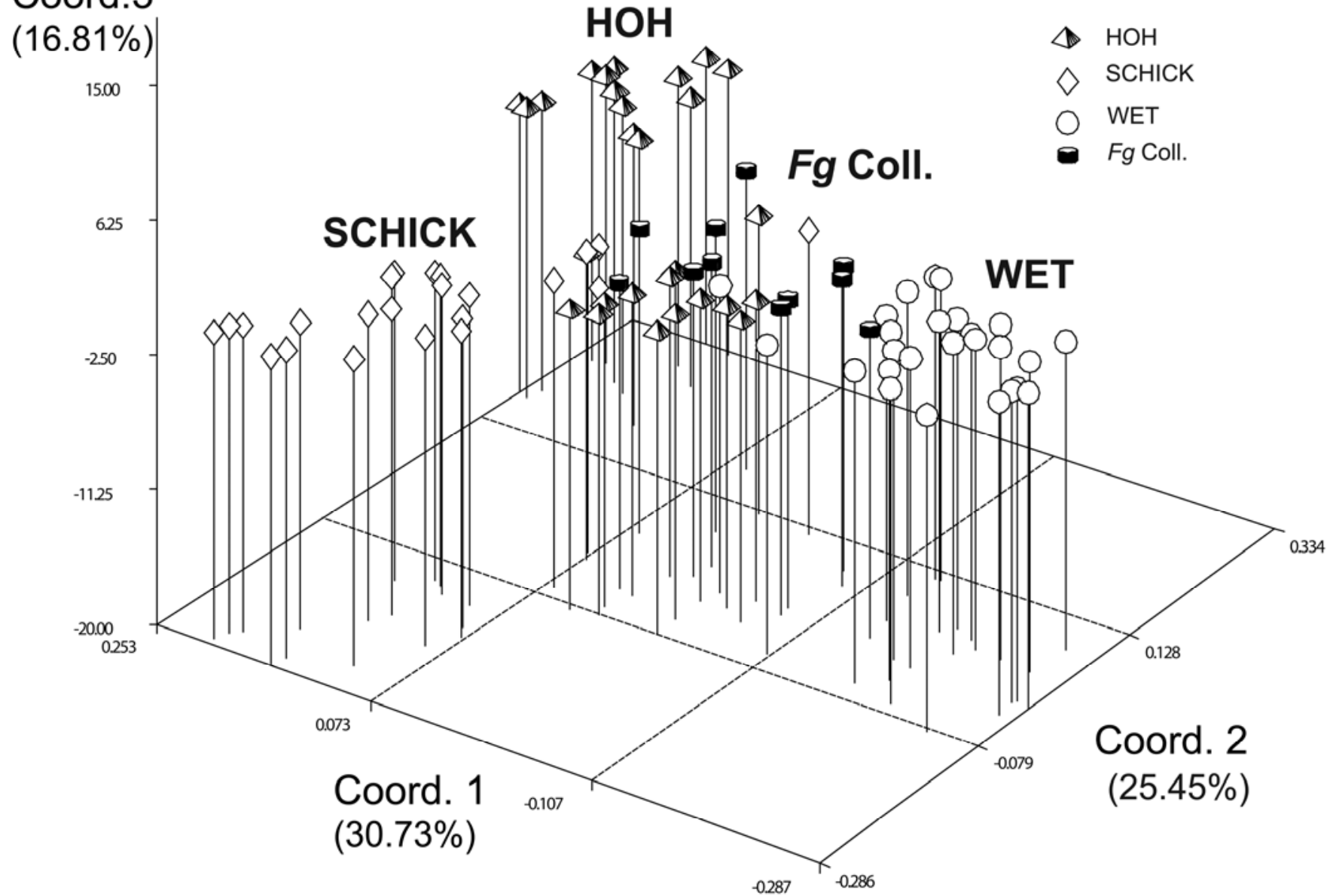

Fig. 3. Simple matching genetic dissimilarity relationship generated by 19 simple-sequence repeat markers of Fusarium graminearum sensu stricto isolates from three field populations (Hohenheim $[\mathrm{HOH}$, Wetze [WET], and Schickelsheim [SCHICK]) (38) and an $F$. graminearum collection (Fg coll.) using principle coordinate analysis. The three coordinates together explain $73 \%$ of the isolate variation. $\mathrm{HOH}=28$ isolates, SCHICK $=23$ isolates, WET $=27$ isolates, and $F g$ coll. $=11$ isolates. 
(data not shown). Accordingly, in the analysis combined across environments, the within-population variance was $\approx 2.5$ times larger than the between-population variance. This type of variance partitioning is well known from allogameous plant species where the largest amount of total variance also can be found within populations $(17,27)$, because outcrossing favors frequent recombination. The latter is not that clear in $F$. graminearum s.s. because it is a homothallic species. Increasing evidence arises, however, from population-genetic studies that outcrossing also should occur in the field $(23,26,38)$. A high level of genetic diversity in $F$. graminearum populations from individual U.S. wheat fields was already described for vegetative compatibility groups (2) and molecular markers (45). Recently, Chen and Zhou (3) first demonstrated sexual crossing of $F$. graminearum s.s. in the field, with outcrossing rates of 6 to $20 \%$.

High molecular diversity was reported from field populations of $F$. graminearum worldwide $(12,16,18,26)$. Accordingly, in this study, a high molecular diversity was detected in each population in terms of Nei's genetic diversity. Although a small number of isolates in the $F$. graminearum collection was used for comparison only, its Nei's genetic diversity value was the highest compared with the other populations (Table 4). This was expected because $F$. graminearum collection isolates were sampled from different continents. Moreover, AMOVA revealed that $73.6 \%$ of the molecular variance was attributed to within-population and $26.4 \%$ to between-population variance. A similar partitioning was obtained in a companion study where a total of 12 populations of F. graminearum s.s. were analyzed, including the German populations from this study (38). PCoA analysis illustrates the small proportion of molecular variance among populations compared with the large variance within each field population, in addition to the high molecular similarity between $F$. graminearum collection and all German field populations (Fig. 3).

Both molecular and phenotypic variances demonstrate a similar high diversity within individual field populations. Similar results were found for comparisons of local field population versus international collections in molecular studies $(23,38)$ and for aggressiveness in young-plant stage (25). The fungal ability to adapt to environmental factors, including resistant cultivars, largely depends on the genetic variation within natural populations governed by the evolutionary forces mutation, recombination system, selection, genetic drift, and gene flow (22). FHB severity as well as DON production of the isolates is a result of predominantly additive gene action (6). Sexual crossing resulted in a recombination of loci that led to transgressions (i.e., progeny that are significantly different from the better parent in their aggressiveness and DON concentration in the host) $(6,41)$. Therefore, it is reasonable to assign the high amount of phenotypic and molecular variation within individual field populations in Germany to sexual recombination with an appreciable outcrossing rate. Other factors that maintain such a high diversity for parasitic ability might be due to balancing selection between the saprophytic and parasitic phases of the pathogen and a low selection pressure by the host that allows a large spectrum of isolates to survive $(23,26)$.

The high diversity within individual field populations as revealed by phenotypic traits and molecular markers as well reflects a high evolutionary potential of $F$. graminearum s.s. (22) with the chance of rapid adaptation to environmental changes, including host resistance. This is expressed by the detected rapid changes in chemotypes $(31,42,47)$ or by resistance to fungicides $(11)$. However, neither host $\times$ isolate interaction (39) nor short-term selection effects have been found among $F$. graminearum isolates due to host genotype (40). Due to the extremely large variation within individual field populations in terms of aggressiveness and DON concentration in the host and the additional impact of sexual recombination on aggressiveness (41), however, it cannot be excluded that growing resistant cultivars based on a few highly effective quantitative trait loci on a large acreage might lead to a gradual increase of mean aggressiveness of $F$. graminearum s.s. populations.

\section{ACKNOWLEDGMENTS}

This research was funded by the State Plant Breeding Institute (720), Universität Hohenheim, Germany, and German Academic Exchange Service (DAAD), Bonn, Germany. We thank H. F. Utz for his effective advices on statistical analyses and B. Lieberherr for her excellent assistance in field work.

\section{LITERATURE CITED}

1. Anonymous. 2010. Descriptive List of Recommended Cultivars (BSL). Landbuch-Verlag, Bundessortenamt, Hannover, Germany. (In German)

2. Bowden, J. L., and Leslie, J. F. 1994. Diversity of Gibberella zeae at small spatial scales. (Abstr.) Phytopathology 84:1140.

3. Chen, Y., and Zhou, M. G. 2009. Sexual recombination of carbendazim resistance in Fusarium graminearum under field conditions. Pest Manage. Sci. 65:398-403.

4. Cochran, W, G., and Cox, G. M. 1957. Experimental Designs, 2nd ed. John Wiley and Sons, Inc., New York.

5. Cowger, C., and Arrellano, C. 2010. Plump kernels with high deoxynivalenol linked to late Gibberella zeae infection and marginal disease conditions in winter wheat. Phytopathology 100:719-728.

6. Cumagun, C. J. R., and Miedaner, T. 2004. Segregation for aggressiveness and deoxynivalenol production of a population of Gibberella zeae causing head blight of wheat. Eur. J. Plant Pathol. 110:789-799.

7. Cumagun, C. J. R., Rabenstein, F., and Miedaner, T. 2004. Genetic variation and covariation for aggressiveness, deoxynivalenol colonization among progeny of Gibberella zeae in wheat. Plant Pathol. 53:446-453.

8. Doohan, F. M., Parry, D. W., Jenkinson, P., and Nicholson, P. 1998. The use of species specific PCR based assays to analyze Fusarium ear blight of wheat. Plant Pathol. 47:197-205.

9. Excoffier, L., and Lischer, H. E. L. 2010. Arlequin suite ver. 3.5: A new series of perform population genetics analyses under Linux and Windows. Mol. Ecol. Res. 10:564-567.

10. Fehr, W. R. 1987. Principles of Cultivar Development, Theory and Technique, Vol. 1. Macmillan Press, New York.

11. Gale, L. R., Chen, L.-F., Hernick, C, A., Takamura, K., and Kistler, H. C. 2002. Population analysis of Fusarium graminearum from wheat fields in eastern China. Phytopathology 92:1315-1322.

12. Gale, L. R., Harrison, S. A., Ward, T. J., O’Donnel, K., Milus, E. A., Gale, S. W., and Kistler, H. C. 2011. Nivalenol type populations of Fusarium graminearum and F. asiaticum are prevalent wheat in southern Louisiana. Phytopathology 101:124-134.

13. Gang, G., Miedaner, T., Schuhmacher, U., Schollenberger, M., and Geiger, H. H. 1998. Deoxynivalenol and nivalenol production by $\mathrm{Fu}$ sarium culmorum isolates differing in aggressiveness toward winter rye. Phytopathology 88:879-884.

14. Gilchrist, L., and Dubin, H. J. 2002. Fusarium head blight. In: Bread Wheat, Improvement and Production. B. C. Curtis, S. Rajaram, and H. G. MacPherson, eds. FAO Press, Rome.

15. Giraud, T., Fournier, E., Vautrin, D., Solignac, M., Vercken, E., Bakan, B., and Brygoo, Y. 2002. Isolation of eight polymorphic microsatellite loci using an enrichment protocol, in the phytopathogenic fungus Fusarium culmorum. Mol. Ecol. Notes 2:121-123.

16. Guo, X. W., Fernando, W. G. D., and Seow-Brock, H. Y. 2008. Population structure chemotype diversity and potential chemotype shifting of Fusarium graminearum in wheat fields of Manitoba. Plant Dis. 92:756762.

17. Hamrick, J. L., and Godt, M. J. W. 1997. Allozyme diversity in cultivated crops. Crop. Sci. 37:26-30.

18. Karugia, G. W., Suga, H., Gale, L. R., Nakajima, T., Tomimura, K., and Hyakumachi, M. 2009. Population structure of Fusarium graminearum species complex from a single Japanese wheat field sampled in two consecutive years. Plant Dis. 93:170-174.

19. Knoll, S., Mulfinger, S., Niessen, L., and Vogel, F. 2002. Rapid preparation of Fusarium DNA from cereals for diagnostic PCR using sonification and an extraction kit. Plant Pathol. 51:728-734.

20. Leslie, J. F., and Summerell, B. A. 2006. The Fusarium Laboratory Manual. Blackwell Professional, Ames, IA.

21. Macdonald, M. V., and Chapman, R. 1997. The incidence of Fusarium moniliforme on maize from Central America, Africa and Asia during 1992-1995. Plant Pathol. 46:112-125.

22. McDonald, B. A., and Linde, C. 2002. Pathogen population genetics evolutionary potential and durable resistance. Annu. Rev. Phytopathol. 40:349-379. 
23. Miedaner, T., Cumagun, C. J. R., and Chakraborty, S. 2008. Population genetics of three important head blight pathogens Fusarium graminearum, $F$. pseudograminearum and F. culmorum. J. Phytopathol. 156:129-139.

24. Miedaner, T., Reinbrecht, C., and Schilling, A. G. 2000. Association among aggressiveness, fungal colonization, and mycotoxin production of 26 isolates of Fusarium graminearum in winter rye head blight. J. Plant Dis. Prot. 107:124-134.

25. Miedaner, T., and Schilling, A. G. 1996. Genetic variation of aggressiveness in individual field populations of Fusarium graminearum and Fusarium culmorum tested on young plants of winter rye. Eur. J. Plant Pathol. 102:823-830.

26. Miedaner, T., Schilling, A. G., and Geiger, H. H. 2001. Molecular genetic diversity and variation for aggressiveness in populations of Fusarium graminearum and Fusarium culmorum sampled from wheat fields in different countries. J. Phytopathol. 149:641-648.

27. Mirdita, V., Dhillon, B. S., Geiger, H. H., and Miedaner, T. 2008. Genetic variation for resistance to ergot (Claviceps purpurea [Fr.] Tul.) among full-sib families of five populations of winter rye (Secale cereale L.). Theor. Appl. Genet. 118:85-90.

28. Müller, H.-M., and Schwadorf, K. 1993. A survey of the natural occurrence of Fusarium toxins in wheat frown in southwestern area of Germany. Mycopathologia 121:115-121.

29. Muthomi, J. W., Dehne, H. W., Oerke, E. C., Mutitu, E. W., and Hindorf, H. 2000. Characterization of Fusarium graminearum and F. culmorum isolates by mycotoxin production and aggressiveness to wheat. Mycol. Res. 16:50-53.

30. Nelson, P. E., Toussoun, T. A., and Marasas, W. F. O. 1983. Fusarium Species: An Illustrated Manual for Identification. Pennsylvania State University, University Park.

31. Nicholson, P., Simpson, D. R., Weston, G., Rezanoor, H. N., Lees, A. K., Parry, D. W., and Joyce, D. 1998. Detection and quantification of Fusarium culmorum and Fusarium graminearum in cereals using PCR assays. Physiol. Mol. Plant Pathol. 53:17-37.

32. Peakall, R., and Smouse, P. E. 2006. GENALEX 6: genetic analysis in Excel: population genetic software for teaching and research. Mol. Ecol. Notes 6:288-295.

33. Reid, L. M., Hamilton, R. I., and Mather, D. E. 1996. Screening maize for resistance to Gibberella ear rot. Tech. Bull. 1996-5E. Eastern Cereal and Oilseed Research Centre, Research Branch, Agriculture and Agri-Food Canada, Ottawa, ON, Canada.

34. Salas, B., Steffenson, B. J., Casper, H. H., Tacke, B., Prom, L. K., Fetch J. R, T. G., and Schwarz, P. B. 1999. Fusarium species pathogenic to barley and their associated mycotoxins. Plant Dis. 83:667-674.

35. SAS Institute, 2004. SAS Online Doc 9.1.2. SAS Institute Inc., Cary, NC.
36. Sokal, S. D., and Michener, C. D. 1958. A statistical method for evaluating systematic relationships. Univ. Kans. Sci. Bull. 38:1409-1438.

37. Suga, H., Gale, L. R., and Kistler, H. C. 2004. Development of VNTR markers for two Fusarium graminearum clade species. Mol. Ecol. Notes 4:468-470.

38. Talas, F., Parzies, H. K., and Miedaner, T. 2011. Diversity in genetic structure and chemotype composition of Fusarium graminearum sensu stricto populations causing wheat head blight in individual fields in Germany. Eur. J. Plant Pathol. 131:39-48.

39. Van Eeuwijk, F. A., Mesterhazy, A., Kling, C. I., Ruckenbauer, P., Saur, L., Bürstmayer, H., Lemmens, M., Keizer, L. C. O., Maurin, N., and Snijders, C. H. A. 1995. Assessing non-specificity of resistance in wheat to head blight caused by inoculation with European strains of Fusarium culmorum, F. graminearum and F. nivale using a multiplicative model for interaction. Theor. Appl. Genet. 90:221-228.

40. Von der Ohe, C., and Miedaner, T. 2011. Competitive aggressiveness in binary mixtures of Fusarium graminearum and $F$. culmorum. J. Phytopathol. 159:401-410.

41. Voss, H. H., Bowden, R. L., Leslie, J. F., and Miedaner, T. 2010. Variation and transgression of aggressiveness to wheat head blight among progeny of two Gibberella zeae crosses of highly aggressive parental isolates. Phytopathology 100:904-912.

42. Ward, T. J., Clear, R. M., Rooney, A. P., O’Donnell, K., Gaba, D., Patrick, S., Starkey, D. E., Gilbert, J., Geiser, D. M., and Nowicki, T. W. 2008. An adaptive evolutionary shift in Fusarium head blight pathogen populations is driving the rapid spread of more toxigenic Fusarium graminearum in North America. Fungal Genet. Biol. 45:473-484.

43. Xu, X.-M., Parry, D. W., Nicholson, P., Thomsett, M. A., Simpson, D., Edwards, S. G., Cooke, B. M., Doohan, F. M., Monaghan, S., Moretti, A., Tocco, G., Mule, G., Hornok, L., Béki, E., Tantnell, J., and Ritieni, A. 2008. Within field variability of Fusarium head blight pathogens and their associated mycotoxins. Eur. J. Plant Pathol. 120:21-34.

44. Yang, L., Van der Lee, T., Yang, X., Yu, D., and Waalwijk, C. 2008. Fusarium populations on Chinese barley show a dramatic gradient in mycotoxin profiles. Phytopathology 98:719-727.

45. Zeller, K. A., Bowden, R. L., and Leslie, J. F. 2003. Diversity of epidemic populations of Gibberella zeae from small quadrates in Kansas and North Dakota. Phytopathology 93:874-880.

46. Zeller, K. A., Bowden, R. L., and Leslie, J. F. 2004. Population differentiation and recombination in wheat scab populations of Gibberella zeae from the United States. Mol. Ecol. 13:653-557.

47. Zhang, H., Zhang, Z., Van der Lee, T., Xu, J., Yang, L., Yu, D., Waalwijk, C., and Feng, J. 2010. Population genetic analyses of Fusarium asiaticum populations from barley suggest a recent shift favoring $3 \mathrm{ADON}$ producers in southern China. Phytopathology 100:328-336. 